\title{
Equilibrium and Thermodynamic Studies on Adsorption of Hexavalent Chromium from Aqueous Solution onto Low Cost Activated Carbon
}

\author{
Umar Yunusa $^{*}$,a , and Muhammad Bashir Ibrahim ${ }^{\mathrm{a}}$
}

Department of Pure and Industrial Chemistry, Bayero University, P.M.B.3011, BUK, Kano-Nigeria

Received: 17 February 2020; Accepted: 17 March 2020; Published: 08 April 2020

\begin{abstract}
The removal of hexavalent chromium $[\mathrm{Cr}(\mathrm{VI})]$ is a challenging task due to its acute toxicity even at low concentration. In the present study, a low-cost activated carbon (LAC) was prepared from desert date seed shell by chemical activation with $\mathrm{H}_{3} \mathrm{PO}_{4}$ and utilized for the removal of hexavalent chromium from aqueous solution. Batch experiments were conducted to investigate the influence of operating variables such as $\mathrm{pH}$, contact time, adsorbent dosage, initial concentration, co-existing ions and temperature. The amount of $\operatorname{Cr}(\mathrm{VI})$ adsorbed was found to vary with solution $\mathrm{pH}$ and maximum adsorption was observed at a $\mathrm{pH}$ value of 2.0. The extent of chromium uptake $\left(\mathrm{mg} \mathrm{g}^{-1}\right.$ ) was found to increase with increase in initial concentration and contact time. The applicability of the four isotherm models for the present equilibrium data follows the sequence: Freundlich $>$ Temkin $>$ Langmuir $>$ Dubinin-Radushkevich. The mean free energy from the Duninin-Radushkevic isotherm model hinted that the adsorption of $\operatorname{Cr}(\mathrm{VI})$ onto the adsorbent surface follows physisorption mechanism. Thermodynamic parameters related to adsorption, Gibbs free energy change $\left(\Delta \mathrm{G}^{\circ}\right)$, enthalpy change $\left(\Delta \mathrm{H}^{\circ}\right)$, entropy change $\left(\Delta \mathrm{S}^{\circ}\right)$, were also calculated and the negative value of $\Delta \mathrm{H}^{\circ}$ indicates the exothermic nature of the adsorption process. The considerable adsorption capacity of $99.09 \mathrm{mg} \mathrm{g}^{-1}$ is a signifier of the suitability of the prepared adsorbent for commercial application. The findings implicated that the adsorbent can be employed in the treatment of Cr-bearing water and wastewater.
\end{abstract}

Index Terms: Activated carbon, Chromium(VI), Desert date, Co-existing ions, Modeling

(C) 2020 Published by MECS Publisher. Selection and/or peer review under responsibility of the Research Association of Mode rn Education and Computer Science

* Corresponding author.

E-mail address: umaryunusa93@gmail.com, mbibrahim.chm@buk.edu.ng 


\section{Introduction}

Heavy metal pollution of industrial effluent is a serious environmental problem due to their nonbiodegradabilty and acute toxicity. The problem becomes more worrying as our population soar and our industrialization becomes more vehement. Many chromium compounds are used in various industries such as electroplating, metal fabrication, dyeing and leather [1]. They also find applications in other industrial processes such as steel production, mining, petroleum refining, wood preservation, anodizing of aluminum, water-cooling, nuclear power plants, cement, ink, ceramic and glass [2]. Generally, industrial effluents contain both the trivalent $\mathrm{Cr}(\mathrm{III})$ and hexavalent $\mathrm{Cr}(\mathrm{VI})$ form of chromium. Among the two forms of chromium, the hexavalent specie is relatively more toxic and is deemed to be carcinogenic [3]. Therefore, it is mandatory to treat chromium-bearing effluents before disposal in to the recipient environment to avoid consequent health issues.

Treatment technologies for remediation of chromium-bearing wastewaters include membrane filtration, ultrafiltration, ion exchange, co-precipitation, electrolytic methods, photocatalysis and adsorption [4]. However, most of these established techniques are not capable of efficiently reducing chromium concentration to tolerable limit [5]. They also suffer from economic and technological drawbacks, such as intensive operation, energy-expensiveness, high processing/operational cost, high chemical consumption and the generation of colossal amount of secondary pollutants [6]. Most conventional techniques are therefore not profitable as industrial-scale method for removal of chromium from aqueous medium [7].

In an effort to enhance removal efficiency, considerable research efforts have been devoted to addressing the shortcomings associated with conventional treatment options, predominantly via adsorption. The use of adsorbents of natural origin has emerged in the recent years as one of the most viable options to established pollutant management strategies [8]. Many literatures have reported the use of various agricultural waste and byproducts such as maize cob [9], sawdust [10], hazelnut shell [11], groundnut hull [12], sugarcane bagasse [13], pea pod peel [14], avocado seed kernel [15], tea waste [16] and olive bagasse [17] as adsorbents for the removal of $\mathrm{Cr}(\mathrm{VI})$ from aqueous solution. However, most of the adsorbents have low adsorption capacity when utilized in their native form. To produce adsorbents with superior performance, the general trend lately has been that of modified adsorbents either by activation, grafting, changing the chemical form or through engineered composite materials [18].

Activated carbons derived from agricultural wastes have been reported to exhibit valuable properties commensurable to those of available commercial active carbon. Actually, wastes from different agro-sources can serve as suitable precursors for making low-cost activated carbons with good adsorption efficiency. Moreover, proper utilization of these wastes can help reduce the burden on the environment in terms of disposal problem. However, no published references were available on the uptake of $\operatorname{Cr}(\mathrm{VI})$ specifically by desert date seed shell activated carbon. Presently, the seed shell is nothing but a waste having no practical utility. Since it is lignocellulosic in nature, it would be highly desirable to utilize such unused agro-waste as an alternative raw material for making activated carbon for chromium removal from water and wastewater. In view of the above, the present work was initiated to make an active carbon from abundant and locally available lignocellulosic waste (desert date seed shell) with objective to employ it as adsorbent for the reclamation of chromium-bearing effluent. The prepared carbon was characterized using electron microscopic technique and $\mathrm{pH}$ point of zero charge (pHpzc). The influence of operating variables such as initial concentration, contact time, adsorbent dose, $\mathrm{pH}$, co-existing ions and temperature were investigated. Equilibrium isotherm models were tested and thermodynamic quantities $(\Delta \mathrm{G}, \Delta \mathrm{H}$ and $\Delta \mathrm{S})$ were evaluated and discussed. Moreover, the adsorptive properties of the newly prepared activated carbon was compared with previously reported adsorbents of similar category. 


\section{Literature Review}

Recently, the removal of hexavalent chromium from aqueous solution using an activated carbon derived from Leucaena leucephala seed pod was investigated. The prepared activated carbon was characterized by proximate analysis, BET surface area measurement, SEM-EDX and FTIR. The obtained results showed that 100 min contact time, $1.0 \mathrm{~g}$ adsorbent dose, $45^{\circ} \mathrm{C}$ temperature and solution $\mathrm{pH}$ of 6.0 resulted in maximum $\mathrm{Cr}(\mathrm{VI})$ uptake. The experimental data better fitted to the Langmuir isotherm with monolayer adsorption capacity of $26.94 \mathrm{mg}$ g-1. The kinetic analysis revealed that pseudo-second-order model fitted well to the acquired experimental data. Thermodynamic parameters showed the process to be spontaneous and endothermic in nature [19].

In another study, modified biochar obtained after hydrothermal carbonization of Lepironia articulate was used for the removal of hexavalent chromium from aqueous medium. The performance of modified biochar was investigated through batch sorption experiments. Results revealed that removal (\%) and the maximum adsorption capacity (qmax) of $\mathrm{Cr}(\mathrm{VI})$ onto the adsorbent increased up to $98.9 \%$ and $28.75 \mathrm{mg}$ g-1 relative to $63.44 \%$ and $21.90 \mathrm{mg}$ g-1 in unmodified biochar at $\mathrm{pH}$ 2.0, $313 \mathrm{~K}$, and $200 \mathrm{mg} \mathrm{dm}-3$ respectively. The sorption kinetics uptake data were best interpreted with pseudo-second-order model, and sorption isotherm was simulated with the Langmuir model. The thermodynamic parameters confirm the adsorption process to be endothermic and spontaneous [20].

Cucumis melo peel activated carbon was utilized for the removal of hexavalent chromium from aqueous solution. Results obtained showed that the maximum removal of $\mathrm{Cr}$ (VI) was found to be $98 \%$ at $\mathrm{pH} 3.0$ with $250 \mathrm{mg}$ of adsorbent when the concentration of the metal solution was $100 \mathrm{mg} \mathrm{dm}-3$. The kinetics was based on pseudo-second-order equation and the equilibrium data was better fitted to Langmuir and Freundlich models [21]. Also, sugarcane bagasse was utilized as a low cost adsorbent for the removal of Cr (VI) in aqueous solution. Result revealed $100 \%$ removal at $\mathrm{pH} 1.5$ where on increasing the $\mathrm{pH}$ to 3.0 the removal efficiency was reduced to $17 \%$ [22].

\section{Materials and Methods}

\subsection{Chemicals}

Potassium dichromate $\left(\mathrm{K}_{2} \mathrm{Cr}_{2} \mathrm{O}_{7}\right)$, phosphoric acid $\left(\mathrm{H}_{3} \mathrm{PO}_{4}\right)$, sodium nitrate $\left(\mathrm{NaNO}_{3}\right)$, sodium carbonate $\left(\mathrm{Na}_{2} \mathrm{CO}_{3}\right)$, sodium chloride $(\mathrm{NaCl})$, sodium hydroxide $(\mathrm{NaOH})$ and hydrochloric acid $(\mathrm{HCl})$ used were of analytical grade obtained from Sigma Aldrich. Deionized water was used in the preparation of all standard solutions. The $\mathrm{Cr}(\mathrm{VI})$ stock solution was prepared by dissolving $2.829 \mathrm{~g}$ of potassium dichromate in $1 \mathrm{dm}^{3}$ deionized water. The needed experimental concentrations were prepared by appropriate dilution of the stock with deionized water. $0.1 \mathrm{~mol} \mathrm{dm}^{-3} \mathrm{HCl}$ and $0.1 \mathrm{~mol} \mathrm{dm}^{-3} \mathrm{NaOH}$ were used to adjust the initial solution $\mathrm{pH}$ depending on the requirement.

\subsection{Equipment}

Microwave Plasma-Atomic Emission Spectrometer (4210 MP-AES; Agilent) was used for the determination of residual Cr(VI) concentration. Incubator shaker (Innova 4000; New Brunswick Scientific) was employed for the agitation of the sample solutions during batch experiments. pH meter (3510; Jenway) was used for $\mathrm{pH}$ measurement. Centrifuge (Centurion 4000 Series) was employed for centrifugation after each adsorption experiment. The thermal treatment during activated carbon preparation was carried out in a muffle furnace (SXL-1008). Surface morphology of the adsorbent was examined using scanning electron microscope 
(PRO: X: Phenonm World 800-07334).

\subsection{Preparation of Activated Carbon}

The preparation of the activated carbon was largely guided by the method described by [23], however with modification in the activating agent used $\left(\mathrm{H}_{3} \mathrm{PO}_{4}\right.$ instead of $\left.\mathrm{KOH}\right)$. The desert date seed shells were first washed thoroughly with water to get rid of surface adhered impurities. They were subsequently air dried for $48 \mathrm{~h}$ and then in an oven at $105^{\circ} \mathrm{C}$ overnight. The dried shells were ground and screened to pass through a 1 $\mathrm{mm}$ sieve to remove larger particles. They were subsequently carbonized at $700^{\circ} \mathrm{C}$ in a muffle furnace for 90 min. The carbonized sample was then mixed with solution of the activating agent such that the mass ratio of $\mathrm{H}_{3} \mathrm{PO}_{4}$ to charcoal was 3:1. This was followed by second heating at $750^{\circ} \mathrm{C}$ for $90 \mathrm{~min}$. The sample was cooled, washed first with $0.1 \mathrm{~mol} \mathrm{dm}^{-3} \mathrm{HCl}$ and then thoroughly with deionized water until a neutral $\mathrm{pH}$ was attained. The desired activated carbon was obtained after drying in an oven at $110^{\circ} \mathrm{C}$ for $24 \mathrm{~h}$.

\subsection{Characterization of Adsorbent}

\subsubsection{Scanning electron microscopy (SEM)/Energy dispersive spectroscopy (EDS)}

The morphological features and elemental composition of the adsorbent were analyzed using SEM/EDS analysis. The samples were placed on brass stubs using adhesive tape on both sides. Scanning were done at an accelerating voltage of $15.00 \mathrm{kV}$ and at x1000 magnifications.

\subsection{2 pH point of zero charge measurements ( $\mathrm{pHpzc}$ )}

The $\mathrm{pH}$ point of zero charge of the LAC was identified using the salt addition method described by [24]. In a series of $50 \mathrm{~cm}^{3}$ centrifuge tubes, $0.2 \mathrm{~g}$ of the adsorbent was added to $40 \mathrm{~cm}^{3}$ of $0.1 \mathrm{~mol} \mathrm{dm}^{-3} \mathrm{NaNO}_{3}$ solution. The $\mathrm{pH}$ was adjusted using $0.1 \mathrm{~mol} \mathrm{dm}^{-3} \mathrm{HCl}$ and $0.1 \mathrm{~mol} \mathrm{dm}^{-3} \mathrm{NaOH}$ to obtain the $\mathrm{pH}$ range of 2-11. The initial $\mathrm{pH}$ values of the supernatant in each tube were denoted as $\mathrm{pH}_{\mathrm{i}}$. The contents were then shaken continuously for $24 \mathrm{~h}$ using an incubator shaker. After settling, the $\mathrm{pH}$ values of the supernatant in each tube were measured and denoted as $\mathrm{pH}_{\mathrm{f}}$. A graph between difference of final and initial $\mathrm{pH}(\Delta \mathrm{pH})$ against $\mathrm{pH}_{\mathrm{i}}$ was plotted to obtain the zero point value of $\mathrm{pH}$ (pHpzc).

\subsection{Batch Adsorption Study}

The influence of initial $\mathrm{Cr}(\mathrm{VI})$ concentration (50-250 $\mathrm{mg} \mathrm{dm}^{-3}$ ), contact time (20-240 min), adsorbent dose (0.1-0.4 g), $\mathrm{pH}$ (2.0-9.0), co-existing ions (0-0.2 $\left.\mathrm{mol} \mathrm{dm}^{-3}\right)$ and temperature $\left(30-50^{\circ} \mathrm{C}\right)$ on the adsorption process were investigated using batch technique. Batch experiments were conducted by contacting a specified amount of adsorbent with $100 \mathrm{~cm}^{3}$ of different $\mathrm{Cr}(\mathrm{VI})$ solutions in a set of conical flasks. The initial solution $\mathrm{pH}$ was adjusted to the desired value and the contents of each flask were agitated in temperature controlled incubator shaker at a constant agitation speed of $150 \mathrm{rpm}$. After attainment of equilibrium, each sample was centrifuged at $1000 \mathrm{rpm}$ for $5 \mathrm{~min}$ and the clear supernatant was decanted. The concentration of residual $\mathrm{Cr}(\mathrm{VI})$ was then analyzed by microwave plasma-atomic emission spectrometer (MP-AES). The amount of $\mathrm{Cr}(\mathrm{VI})$ adsorbed per gram of adsorbent at equilibrium $\left(\mathrm{q}_{\mathrm{e}}\right)$ and the removal percentage $(\mathrm{R} \%)$ were evaluated using Eqs. (1)-(2), respectively:

$$
\mathrm{qe}=\left(\frac{\mathrm{Co}-\mathrm{Ce}}{\mathrm{m}}\right) \mathrm{V}
$$




$$
\mathrm{R}(\%)=\left(\frac{\mathrm{Co}-\mathrm{Ce}}{\mathrm{Co}}\right) \times 100
$$

where, $C_{o}$ is the initial concentration of adsorbate $\left(\mathrm{mg} \mathrm{dm}^{-3}\right), \mathrm{C}_{\mathrm{e}}$ is the concentration of adsorbate at equilibrium $\left(\mathrm{mg} \mathrm{dm}^{-3}\right), \mathrm{V}$ is the volume of adsorbate solution $\left(\mathrm{dm}^{3}\right)$ and $\mathrm{m}$ is the mass of the adsorbent $(\mathrm{g})$.

\subsubsection{Influence of contact time}

A specified amount of the adsorbent was added to a series of $100 \mathrm{~cm}^{3}$ of the $\operatorname{Cr}(\mathrm{VI})$ solution of fixed concentration (150 $\left.\mathrm{mg} \mathrm{dm}^{-3}\right)$. The contents were agitated for different time intervals $(20,40,60,80,100,120$, 180 and $240 \mathrm{~min})$ under room temperature $\left(30 \pm 2{ }^{\circ} \mathrm{C}\right)$. The mixture after each time interval were centrifuged immediately and subjected to analysis.

\subsubsection{Influence of adsorbent dose}

The influence of adsorbent dosage was investigated by agitating $100 \mathrm{~cm}^{3}$ of $\mathrm{Cr}(\mathrm{VI})$ solutions of fixed concentration (150 $\mathrm{mg} \mathrm{dm}^{-3}$ ) with varying amount of adsorbent $(0.1,0.2,0.3$ and $0.4 \mathrm{~g}$ ) for a period of 240 min. After the completion of time, the mixture was centrifuged, and the residual metal ion in the supernatant was analyzed.

\subsubsection{Influence of $\mathrm{pH}$}

The influence of $\mathrm{pH}$ on $\mathrm{Cr}(\mathrm{VI})$ adsorption by LAC was investigated over a $\mathrm{pH}$ range of 2.0-9.0. A $100 \mathrm{~cm}^{3}$ of $\mathrm{Cr}(\mathrm{VI})$ solution of fixed concentration $\left(150 \mathrm{mg} \mathrm{dm}^{-3}\right)$ was contacted with $0.2 \mathrm{~g}$ of the adsorbent. The mixtures were agitated for $100 \mathrm{~min}$ at the aforementioned temperature. After centrifugation, the supernatant was analyzed for residual metal concentration.

\subsubsection{Influence of co-existing ions}

The influence of co-existing ions was investigated by agitating $100 \mathrm{~cm}^{3} \mathrm{Cr}(\mathrm{VI})$ solutions with varying concentration of $\mathrm{NaCl}, \mathrm{NaNO}_{3}$ and $\mathrm{NaNO}_{3}\left(0,0.05,0.1,0.15\right.$, and $\left.0.2 \mathrm{~mol} \mathrm{dm}{ }^{-3}\right)$ till equilibrium time. All other parameters were kept constant. The contents were then centrifuged and analyzed for residual metal concentration.

\subsubsection{Equilibrium studies: influence of initial Cr(VI) concentration}

The influence of initial concentration was studied at different $\mathrm{Cr}(\mathrm{VI})$ initial concentration ranging from $50-250 \mathrm{mg} \mathrm{dm}^{-3}$. The initial $\mathrm{pH}$ of all solutions was adjusted to optimized $\mathrm{pH}$ value (2.0) and then contacted with $0.2 \mathrm{~g}$ of the adsorbent. The contents were then agitated for predetermined equilibrium time of $100 \mathrm{~min}$ under room temperature $\left(30 \pm 2{ }^{\circ} \mathrm{C}\right)$. The mixture was centrifuged and the supernatant was analyzed for the concentration of unadsorbed metal ion.

\subsubsection{Thermodynamic studies: influence of temperature}

For the influence of temperature, $0.2 \mathrm{~g}$ of LAC was added into $100 \mathrm{~cm}^{3}$ of $\mathrm{Cr}(\mathrm{VI})$ solutions (150 and 200 $\mathrm{mg} \mathrm{dm}{ }^{-3}$ ). Batch experiments were performed at different temperatures of 30 , 40 , and $50^{\circ} \mathrm{C}$ while keeping all other experimental parameters constant (equilibrium time, optimum $\mathrm{pH}$ and dosage). After each adsorption 
experiment, residual concentrations of adsorbate were analyzed.

\section{Results and Discussion}

\subsection{Characterization of the Adsorbent}

\subsubsection{SEM/EDS}

The morphological characteristics of adsorbent influence its performance in various applications. SEM is a very vital technique to probe the surface morphology of adsorbents. Fig. 1a displays the micrograph of the adsorbent before $\mathrm{Cr}(\mathrm{VI})$ adsorption. It is seen the adsorbent tend to possess highly rough heterogeneous surface with distinct crevices resulting from subjecting the material to thermal processes. However, after adsorption of $\mathrm{Cr}(\mathrm{VI})$, the surface of the LAC is relatively smooth (Fig. 1b). This is probably due to effective interaction of the adsorbate with the adsorbent's surface. EDS spectrum (Fig. 2) of the LAC revealed the peaks for $\mathrm{C}, \mathrm{O}, \mathrm{N}, \mathrm{Cl}$ and $\mathrm{P}$ elements with a high $\mathrm{C}$ content (82.93 \%).

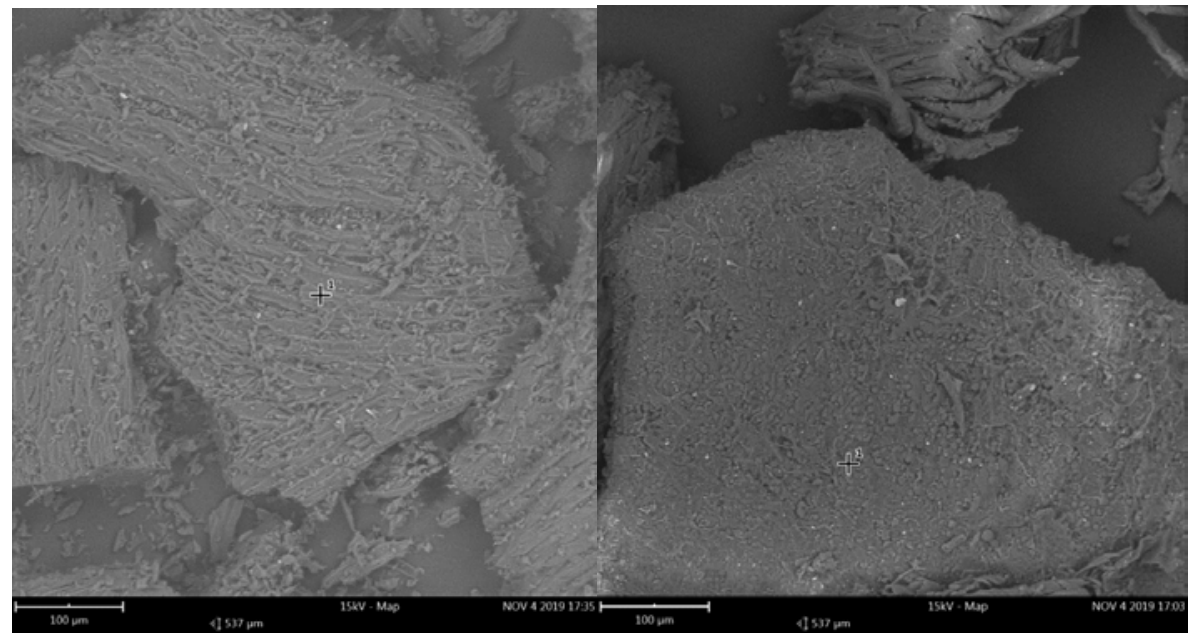

Fig. 1. SEM micrograph of LAC (a) before adsorption and (b) after adsorption

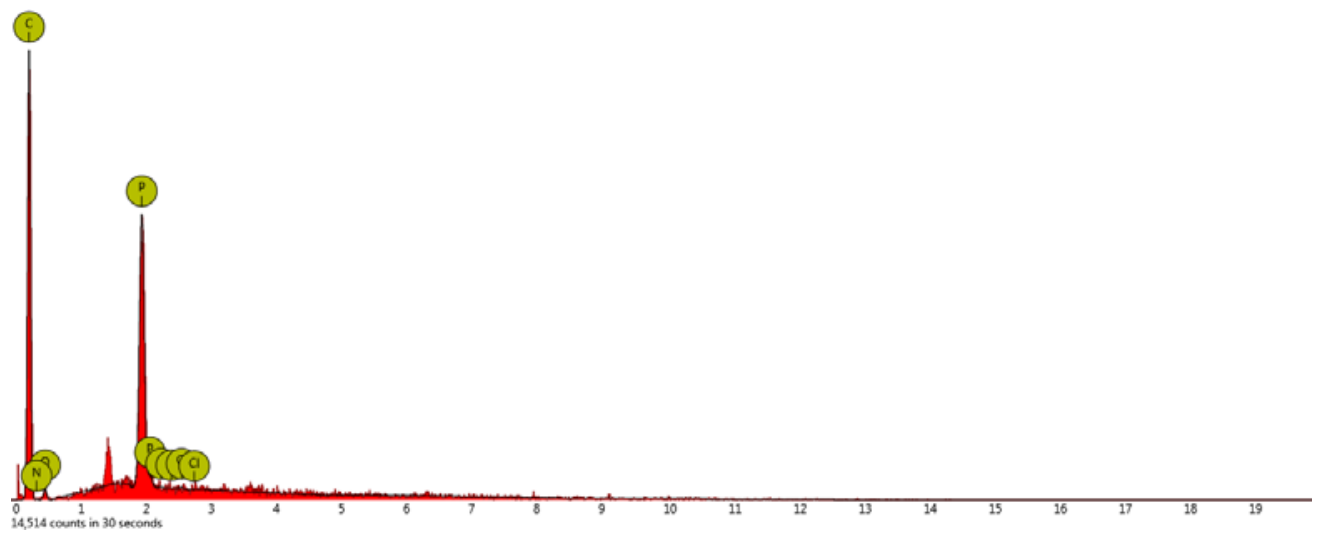

Fig. 2 EDS spectrum of LAC 


\subsection{2 $\mathrm{pH}$ of point of Zero Charge $\mathrm{pH}_{P Z C}$}

The determination of $\mathrm{pH}_{\mathrm{PZC}}$ was carried out to determine the value of $\mathrm{pH}$ for which the surface of LAC bears a net charge of zero. $\mathrm{pH}_{\mathrm{pzc}}$ plays vital role in surface characterization as it determines how easily an adsorbent can bind potentially harmful ions [25]. The zero point charge of the adsorbent is 6.4 (Fig. 3). The implication of this value is that at solution $\mathrm{pH}$ greater than 6.4, the surface of the adsorbent bears a net positive charge, thus favoring the sorption of cationic species. Conversely, for solution $\mathrm{pH}$ less than 6.4, the adsorbent surface is negatively charged and therefore promoting the adsorption of anionic species [26]. Since $\mathrm{Cr}(\mathrm{VI})$ exist in aqueous solution in different anionic forms, it can be suggested that the adsorption process will be favorable when the LAC surface is positive.

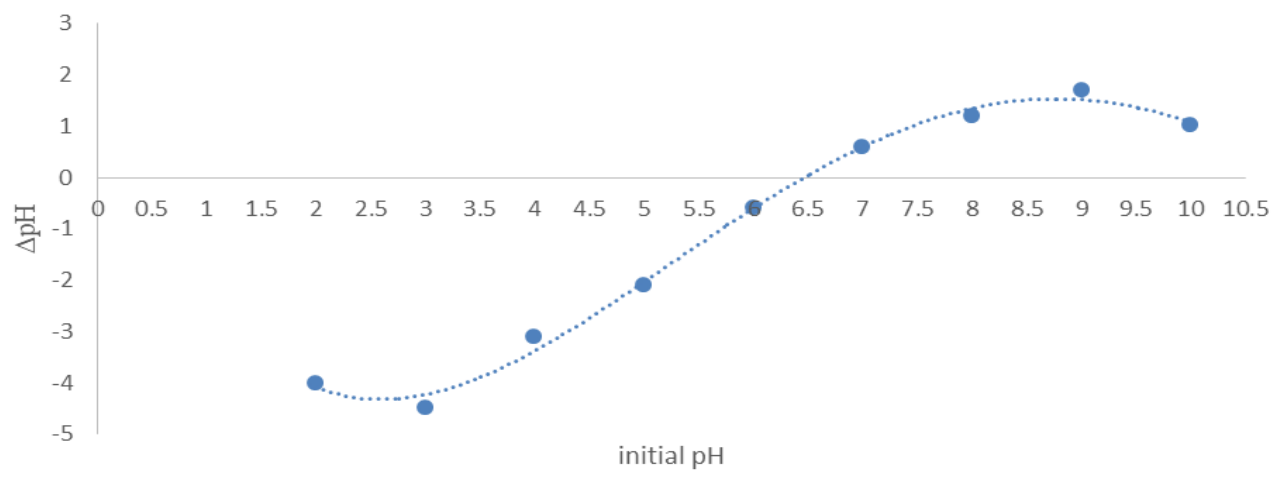

Fig. 3. Determination of $\mathrm{pH}_{\mathrm{PZC}}$ of LAC

\subsection{Influence of contact time and adsorbent dose}

The influence of adsorbent dose and contact time on the $\mathrm{Cr}(\mathrm{VI})$ uptake by LAC is illustrated in Fig. 4. It is seen that the extent of $\mathrm{Cr}(\mathrm{VI})$ adsorption increases with increasing contact time up to around 100 minutes and then tends to equilibrium thereafter. After attaining the equilibrium, further adsorption was insignificant as a function of contact time under the employed experimental conditions. In the early stages, there are substantial amount of vacant binding sites on the adsorbent accessible for adsorption. As the binding sites become occupied, the rate of adsorption decline and ultimately becomes nearly steady at equilibrium [27]. It is observed that the $\mathrm{Cr}(\mathrm{VI})$ adsorption capacity decreases as the dosage of the adsorbent increases. It is obvious from Fig. 4 that the adsorption capacities decreased from 62.1 to $30.9 \mathrm{mg}$ g- 1 as the adsorbent dosage was increased from 0.1 to $0.4 \mathrm{~g}$. It was also observed that the contact time required for attainment of equilibrium was dependent on the dose of the adsorbent used. For the adsorbent dose of 0.1, 0.2, 0.3 and $0.4 \mathrm{~g}$, the time required for the adsorption to attain equilibrium were: 120, 100, 80 and $80 \mathrm{~min}$, respectively. The decrease in $\mathrm{Cr}(\mathrm{VI})$ adsorption capacity with increase in dosage is attributed to unsaturation of many active sites of the adsorbent during the adsorption process [28]. A similar trend was highlighted in the adsorption of $\mathrm{Cr}(\mathrm{VI})$ using diphenylcarbazide-grafted macadamia nutshell powder[29]. 


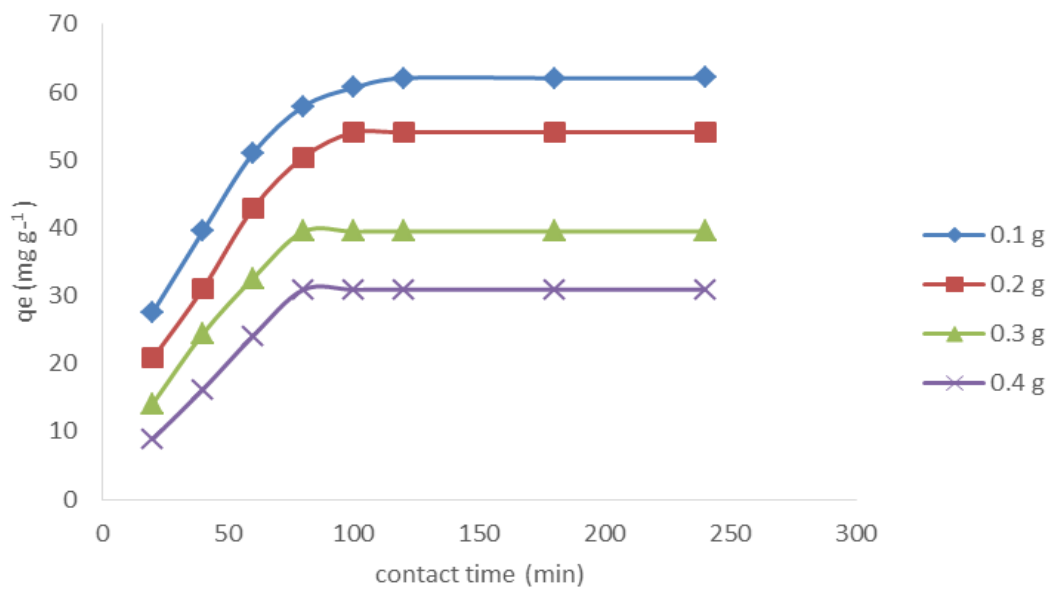

Fig. 4. Influence of contact time and adsorbent dose on $\mathrm{Cr}(\mathrm{VI})$ uptake (Conditions: initial concentration $150 \mathrm{mg} \mathrm{dm}^{-3}$, temperature $30 \pm$ $\left.2^{\circ} \mathrm{C}\right)$

\subsection{Influence of $p H$}

The $\mathrm{pH}$ of the aqueous medium is an important parameter that influence the adsorption process. It affects not only the surface charge of the adsorbent, but also the degree of speciation and ionization of the adsorbate during adsorption [30,31]. To investigate the effect of $\mathrm{pH}$ on the adsorption process, the $\mathrm{pH}$ solution was varied from 2.0 to 9.0 and the result was illustrated in Fig. 5. It can be observed that increasing the solution $\mathrm{pH}$ from 2.0 to 9.0 results in decrease in adsorption capacity from 62.1 to $17.79 \mathrm{mg} \mathrm{g}^{-1}$; so we can deduce that $\mathrm{pH} 2$ is the optimum $\mathrm{pH}$ value for the adsorption of $\mathrm{Cr}(\mathrm{VI})$ on the adsorbent. This could be explained by the fact that $\mathrm{Cr}(\mathrm{VI})$ exist in the form of several species such as $\mathrm{HCrO}_{4}^{-}, \mathrm{Cr}_{2} \mathrm{O}_{7}{ }^{2-}, \mathrm{CrO}_{4}{ }^{2-}, \mathrm{Cr}_{3} \mathrm{O}_{10}{ }^{2-}, \mathrm{H}_{2} \mathrm{CrO}_{4}^{-}$, etc depending on the aqueous solution $\mathrm{pH}$ and concentration [32]. $\mathrm{HCrO}_{4}{ }^{-}$and $\mathrm{Cr}_{2} \mathrm{O}_{7}{ }^{2-}$ predominantly exist at solution $\mathrm{pH}$ within the range of 2.0-6.0. It is also established that $\mathrm{HCrO}_{4}{ }^{-}$is the dominant form of $\mathrm{Cr}(\mathrm{VI})$ at $\mathrm{pH} 2.0$ [33]. Raising $\mathrm{pH}$ shifts the concentration of $\mathrm{HCrO}_{4}^{-}$to other forms, $\mathrm{Cr}_{2} \mathrm{O}_{7}{ }^{2-}$ and $\mathrm{CrO}_{4}{ }^{2-}$. Therefore, maximum adsorption at $\mathrm{pH} 2$ indicates that the adsorbent preferentially adsorbed the $\mathrm{HCrO}_{4}{ }^{-}$form of $\mathrm{Cr}(\mathrm{VI})$ anions [34]. In this context, it is imperative to comment that the $\mathrm{pH}_{\mathrm{pzc}}$ of the adsorbent earlier determined in Fig. 3 was 6.4. This reflects that the favorable condition for adsorption of $\mathrm{HCrO}_{4}{ }^{-}$on $\mathrm{LAC}$ surface is the medium having $\mathrm{pH}$ less than 6.5. Hence, the observed higher adsorption at acidic medium can be ascribed to the strong electrostatic attraction between positively charged adsorbent and $\mathrm{HCrO}_{4}{ }^{-}$. Conversely, the reduced adsorption at higher $\mathrm{pH}$ may presumably be due to competitive adsorption between chromate and hydroxyl ions. Similar trend was highlighted in the adsorption of $\mathrm{Cr}(\mathrm{VI})$ from aqueous solution using various adsorbents [35-37]. 


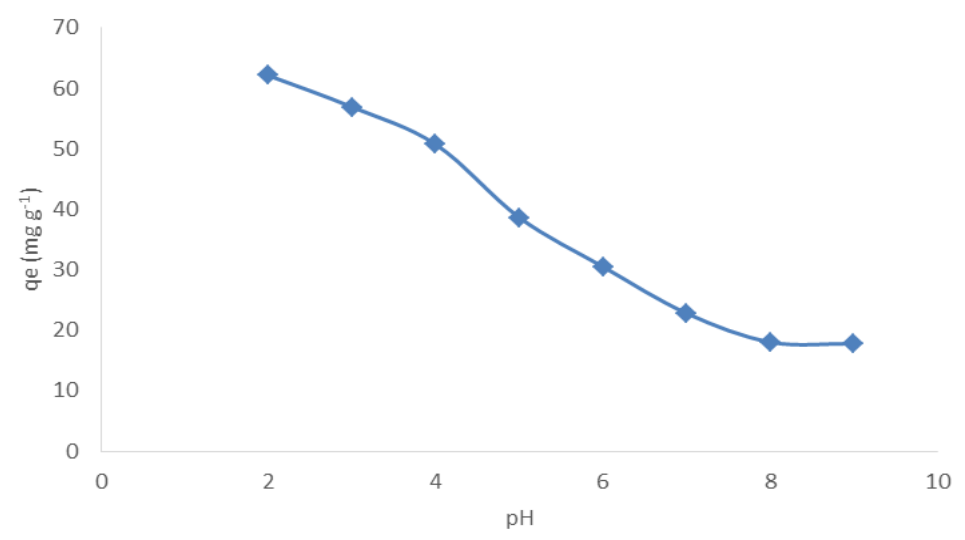

Fig. 5. Influence of $\mathrm{pH}$ on $\mathrm{Cr}(\mathrm{VI})$ uptake (Conditions: initial concentration $150 \mathrm{mg} \mathrm{dm}^{-3}$, adsorbent dose $0.2 \mathrm{~g}$, temperature $30 \pm 2^{\circ} \mathrm{C}$ )

\subsection{Influence of co-existing ions}

The real chromium containing effluents are typically associated with the presence of ionic species such as $\mathrm{Na}^{+}, \mathrm{Cu}^{2+}, \mathrm{NO}_{3}^{-}, \mathrm{CO}_{3}{ }^{2-}, \mathrm{SO}_{4}{ }^{2-}$ and $\mathrm{Cl}^{-}$. It is therefore essential to study the influence of these co-existing ions on the removal of $\mathrm{Cr}(\mathrm{VI})$ from aqueous solutions. Fig. 6 illustrate the effect of salt concentration on the adsorption of $\mathrm{Cr}(\mathrm{VI})$. It is seen that as the as the salt concentration increases from 0.0 to $0.2 \mathrm{~mol} \mathrm{dm}^{-3}$, the adsorption capacity of LAC reduces from 61.9 to $45.5,50.81,53.9 \mathrm{mg} \mathrm{g}^{-1}$ in the presence of $\mathrm{NaCl}, \mathrm{NaNO}_{3}$ and $\mathrm{Na}_{2} \mathrm{CO}_{3}$ respectively. The decrease in amount of $\mathrm{Cr}(\mathrm{VI})$ adsorbed with an increase in salt concentration could be attributed to competition for available active sites between the $\mathrm{HCrO}_{4}{ }^{-}$and the negatively charged $\mathrm{Cl}^{-}{ }_{\text {(aq) }}, \mathrm{NO}_{3}^{-}{ }_{\text {(aq) }}$ and $\mathrm{CO}_{3}{ }^{2-}$ (aq) being introduced. It is also observed that $\mathrm{Cl}^{-1}$ ions reduce the uptake of $\mathrm{Cr}(\mathrm{VI})$ by LAC more than $\mathrm{NO}_{3}{ }^{-}$and $\mathrm{CO}_{3}{ }^{2-}$ ions. This was attributed to the faster diffusion rate of $\mathrm{Cl}^{-}$ions on the adsorbent, than $\mathrm{HCrO}_{4}{ }^{2-}$. Similar observations were previously reported on the removal of $\mathrm{Cr}(\mathrm{VI})$ by acid functionalized nanoporous carbon [38].

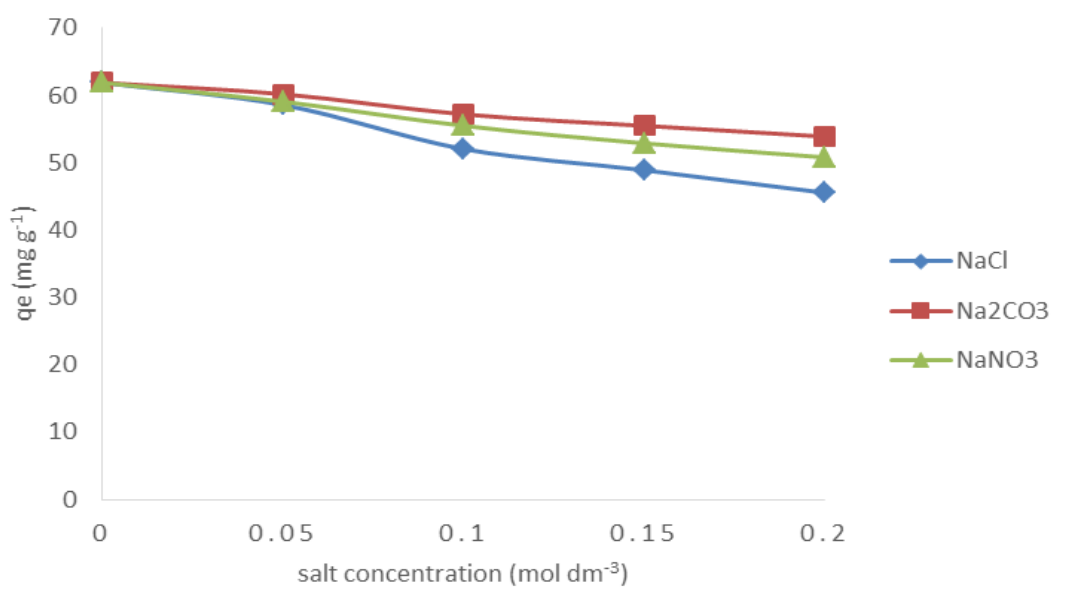

Fig. 6. Influence of co-existing ions on $\mathrm{Cr}(\mathrm{VI})$ uptake (Conditions: initial concentration $150 \mathrm{mg} \mathrm{dm}^{-3}, \mathrm{pH} 2.0$, temperature $30 \pm 2^{\circ} \mathrm{C}$ ) 


\subsection{Influence of initial concentration}

The variation of equilibrium amount of $\mathrm{Cr}(\mathrm{VI})$ adsorbed with initial concentration is depicted in Fig. 7. It is

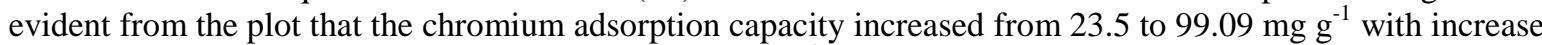
in initial adsorbate concentration from 50 to $250 \mathrm{mg} \mathrm{dm}^{-3}$. This happened due to availability of large number of adsorbate molecules in the aqueous phase enhancing the interaction between the metal ions and LAC. Furthermore, higher metal concentration provided increase in driving force of the concentration gradient to overwhelm all mass transfer resistance of $\mathrm{Cr}(\mathrm{VI})$ ions between liquid and solid phases. Consequently, the probability of collision between the adsorbate and adsorbent active sites increase and thus leading to higher $\mathrm{Cr}(\mathrm{VI})$ uptake $[39,40]$. These observations are consistent with previous reports [41,42].

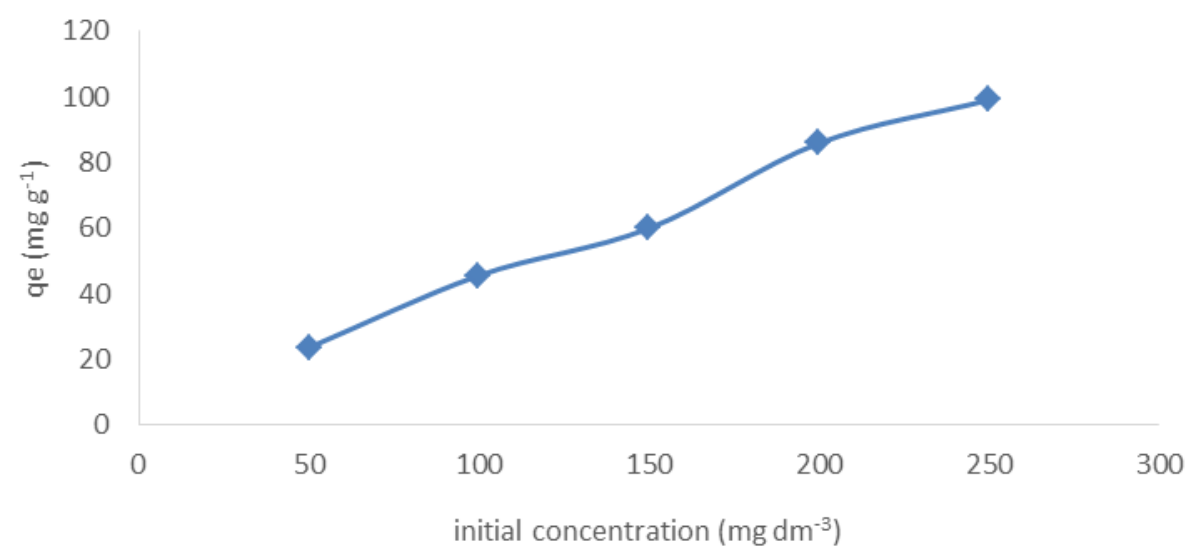

Fig. 7. Influence of initial concentration on $\mathrm{Cr}(\mathrm{VI})$ uptake (Conditions: adsorbent dose $0.2 \mathrm{~g}, \mathrm{pH} 2.0$, temperature $30 \pm 2^{\circ} \mathrm{C}$ )

\subsection{Adsorption Isotherms}

Isotherm models play significant role in describing the behavior of adsorbate-adsorbent interaction. Equilibrium isotherms, namely Langmuir, Freundlich, Temkin and Dubinin-Radushkevic were employed to analyze the adsorption data of $\mathrm{Cr}(\mathrm{VI})$ on the adsorbent, and their linear equations were expressed below, respectively [43]:

$$
\begin{aligned}
& \frac{\mathrm{C}_{\mathrm{e}}}{\mathrm{q}_{\mathrm{e}}}=\frac{1}{\mathrm{~K}_{\mathrm{L}} \mathrm{q}_{\max }}+\frac{\mathrm{C}_{\mathrm{e}}}{\mathrm{q}_{\max }} \\
& \ln \mathrm{q}_{\mathrm{e}}=\ln \mathrm{K}_{\mathrm{f}}+\frac{1}{\mathrm{n}} \ln \mathrm{C}_{\mathrm{e}} \\
& \mathrm{q}_{\mathrm{e}}=\mathrm{B}_{\mathrm{T}} \ln \mathrm{C}_{\mathrm{e}}+\mathrm{B}_{\mathrm{T}} \ln \mathrm{K}_{\mathrm{T}} \\
& \ln \mathrm{q}_{\mathrm{e}}=\ln \mathrm{q}_{\mathrm{m}}-\beta \varepsilon^{2}
\end{aligned}
$$

where; $\mathrm{q}_{\mathrm{e}}$ is the adsorption capacity ( $\mathrm{mg} \mathrm{g}^{-1}$ ) of the adsorbent at equilibrium, $\mathrm{q}_{\max }$ is the maximum adsorption capacity $\left(\mathrm{mg} \mathrm{g}^{-1}\right)$ to form a complete monolayer coverage on the surface at high equilibrium adsorbate concentration $\left(\mathrm{C}_{\mathrm{e}}\right)\left(\mathrm{mg} \mathrm{dm}^{-3}\right), \mathrm{K}_{\mathrm{L}}\left(\mathrm{L} \mathrm{mg}^{-1}\right)$ is Langmuir constant related to affinity between the adsorbate and 
adsorbent, $\mathrm{B}_{\mathrm{T}}\left(\mathrm{J} \mathrm{mol}^{-1}\right)$ and $\mathrm{K}_{\mathrm{T}}\left(\mathrm{L} \mathrm{mg}^{-1}\right)$ are Temkin constant and maximum binding energy respectively, $\varepsilon$ is the polyani potential, $\beta$ is a constant related to the mean adsorption energy $\left(\mathrm{mol}^{2} \mathrm{~kJ}^{-2}\right), \mathrm{K}_{\mathrm{F}}\left(\mathrm{L} \mathrm{mg}^{-1}\right)$ and $\mathrm{n}$ are Freundlich constants related with the adsorption capacity and adsorption intensity, respectively.

The fitted isotherm plots are shown in Fig. 8(a-d) and the parameters concerning the isotherms are summarized in Table 1. In the light of the values of coefficient of determination $\left(\mathrm{R}^{2}\right)$, it can be observed that the experimental data exhibited better fit to the Freundlich model in comparison to the other three models. This implies that the removal of chromium occurred via multilayer adsorption on heterogeneous adsorption sites. The Freundlich model $\mathrm{n}$ value obtained was greater than 1.0 indicating that the adsorbate was adsorbed by LAC easily [44]. The maximum monolayer adsorption capacity of the adsorbent for $\mathrm{Cr}(\mathrm{VI})$ was found to be $136.99 \mathrm{mg} \mathrm{g}^{-1}$ at $303 \mathrm{~K}$. The calculated value of $\mathrm{R}_{\mathrm{L}}$ was in the range of $0-1$ which indicated favorable adsorption of the adsorbate on the adsorbent. The maximum adsorption capacity, $\mathrm{q}_{\mathrm{m}}$ obtained for the $\mathrm{D}-\mathrm{R}$ isotherm model was $77.44 \mathrm{mg} \mathrm{g}^{-1}$ which is less in comparison to the Langmuir model $\left(136.99 \mathrm{mg} \mathrm{g}^{-1}\right)$. The mean free energy of adsorption (E) was obtained as $0.5 \mathrm{~kJ} \mathrm{~mol}^{-1}$ i.e lower than $8.0 \mathrm{~kJ} \mathrm{~mol}^{-1}$. This indicates that the adsorption mechanism is governed by physical adsorption [45].
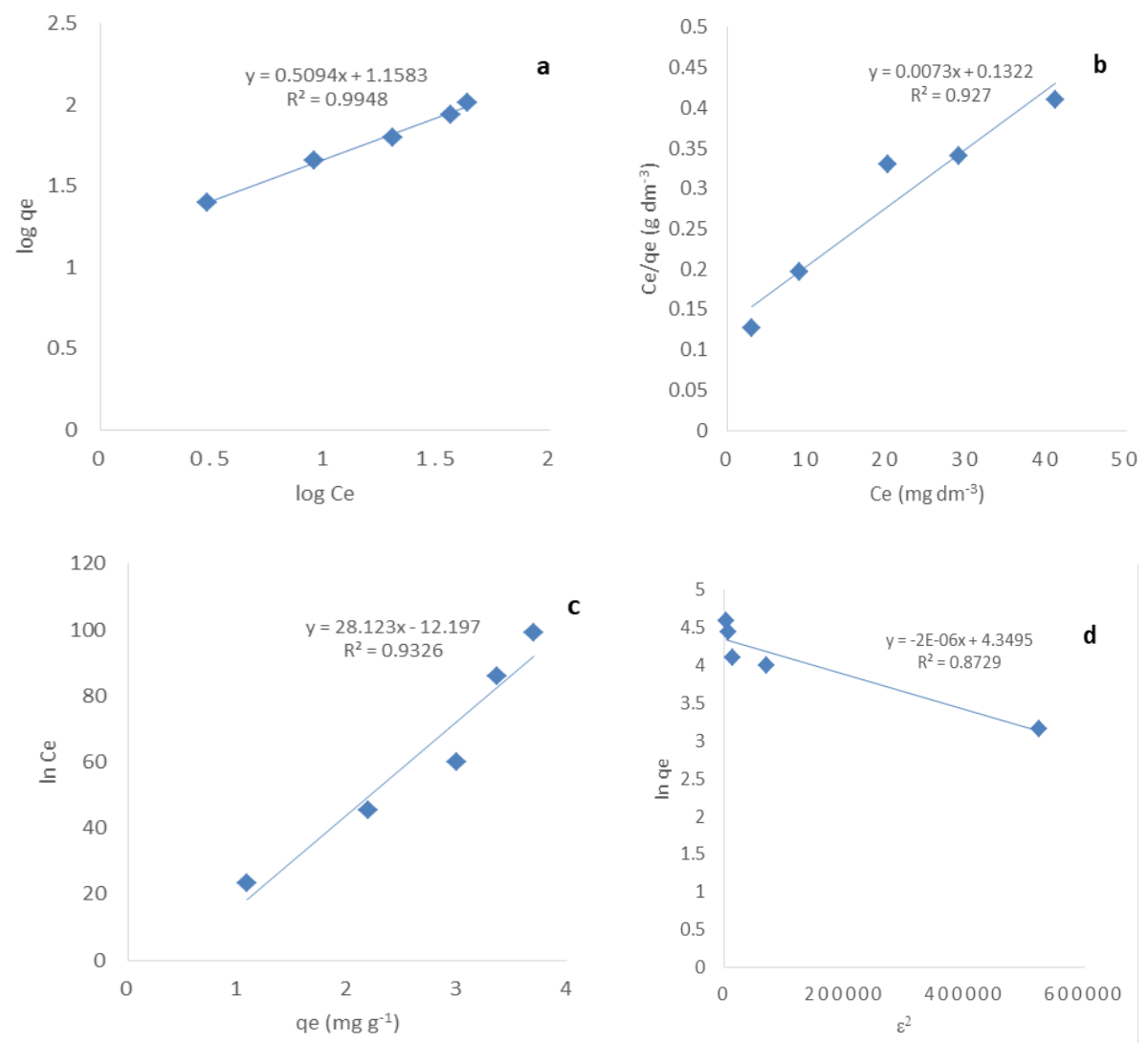

Fig. 8. The fitting results of (a) Freundlich model (b) Langmuir model (c) Temkin model, and (d) Dubinin-Radushkevich model 
Table 1. Isotherm parameters for $\mathrm{Cr}(\mathrm{VI})$ adsorption onto LAC

\begin{tabular}{lll}
\hline Isotherm models & Parameters & Values \\
\hline Langmuir & $\mathrm{q}_{\max }\left(\mathrm{mg} \mathrm{g}^{-1}\right)$ & 136.99 \\
& $\mathrm{~K}_{\mathrm{L}}\left(\mathrm{dm}^{3} \mathrm{mg}^{-1}\right)$ & 0.06 \\
& $\mathrm{R}_{\mathrm{L}}$ & 0.25 \\
& $\mathrm{R}^{2}$ & 0.9270 \\
Freundlich & & 14.40 \\
& $\mathrm{~K}_{\mathrm{F}}\left(\mathrm{dm}^{3} \mathrm{mg}^{-1}\right)$ & 1.96 \\
$\mathrm{n}$ & 0.9948 \\
Temkin & $\mathrm{R}^{2}$ & 0.65 \\
& $\mathrm{~K}_{\mathrm{T}}\left(\mathrm{dm}^{3} \mathrm{mg}^{-1}\right)$ & 28.12 \\
Dubinin- Radushkevich & $\mathrm{B}_{\mathrm{T}}\left(\mathrm{J} \mathrm{mol}^{-1}\right)$ & 0.9326 \\
& $\mathrm{R}^{2}$ & 77.44 \\
& $\mathrm{q}_{\mathrm{m}}\left(\mathrm{mg} \mathrm{g}^{-1}\right)$ & $2 \times 10^{-6}$ \\
& $\beta\left(\mathrm{mol}^{2} \mathrm{~J}^{-2}\right)$ & 0.50 \\
& $\mathrm{E}\left(\mathrm{kJ} \mathrm{mol}^{-1}\right)$ & 0.8729 \\
\hline
\end{tabular}

\subsection{Adsorption Thermodynamics}

Thermodynamic parameters such as changes in enthalpy $\left(\Delta \mathrm{H}^{\circ}\right)$, entropy $\left(\Delta \mathrm{S}^{\circ}\right)$ and Gibbs free energy $\left(\Delta \mathrm{G}^{\circ}\right)$ for the adsorption of $\mathrm{Cr}(\mathrm{VI})$ (at initial concentration of 150 and $200 \mathrm{mg} \mathrm{dm}^{-3}$ ) by LAC were calculated using the following equations [46], and their values are presented in Table 2.

$$
\begin{aligned}
\mathrm{K}_{\mathrm{c}} & =\frac{\mathrm{C}_{\mathrm{ADS}}}{\mathrm{Ce}} \\
\Delta \mathrm{G} & =-\mathrm{RT} \ln \mathrm{K}_{\mathrm{c}} \\
\ln \mathrm{Kc} & =-\frac{\Delta \mathrm{H}^{\circ}}{\mathrm{RT}}+\frac{\Delta \mathrm{S}^{\circ}}{\mathrm{R}}
\end{aligned}
$$

where, $\mathrm{C}_{\mathrm{ADS}}$ and $\mathrm{C}_{\mathrm{e}}\left(\mathrm{mg} \mathrm{dm}^{-3}\right)$ are equilibrium concentration of $\mathrm{Cr}(\mathrm{VI})$ on the adsorbent and in the liquid phase, respectively, $\mathrm{K}_{\mathrm{c}}$ is the equilibrium constant of adsorption, $\mathrm{R}$ is the gas constant $\left(8.314 \mathrm{~J} \mathrm{~K}^{-1} \mathrm{~mol}^{-1}\right)$ and $\mathrm{T}$ is the temperature $(\mathrm{K})$.

A plot of $\ln \mathrm{K}_{\mathrm{c}}$ versus $1 / \mathrm{T}$ according to Eq. 9 is shown in Fig. 9. From the plot, both the change in enthalpy $\left(\Delta \mathrm{H}^{\circ}\right)$ and the entropy $\left(\Delta \mathrm{S}^{\circ}\right)$ were determined from the slope and intercept respectively. The negative value of $\Delta \mathrm{H}^{\circ}$ is consistent with the exothermic nature of the adsorption process while the negative value of $\Delta \mathrm{S}^{\circ}$ reflects the affinity of the adsorbent towards the adsorbate [46]. From Eq. 8 the values of change in Gibbs free energy was evaluated and found to be negative in the temperature range studied. This indicates the spontaneity of $\mathrm{Cr}(\mathrm{VI})$ adsorption onto LAC. Furthermore, the $\Delta \mathrm{G}$ values become more negative with decreasing temperature of the system. This signifies that the adsorption process was more favorable at lower temperature. Similar trend in thermodynamics has been observed in the study of adsorption of $\mathrm{Cr}(\mathrm{VI})$ using functionalized chitosan [48]. 


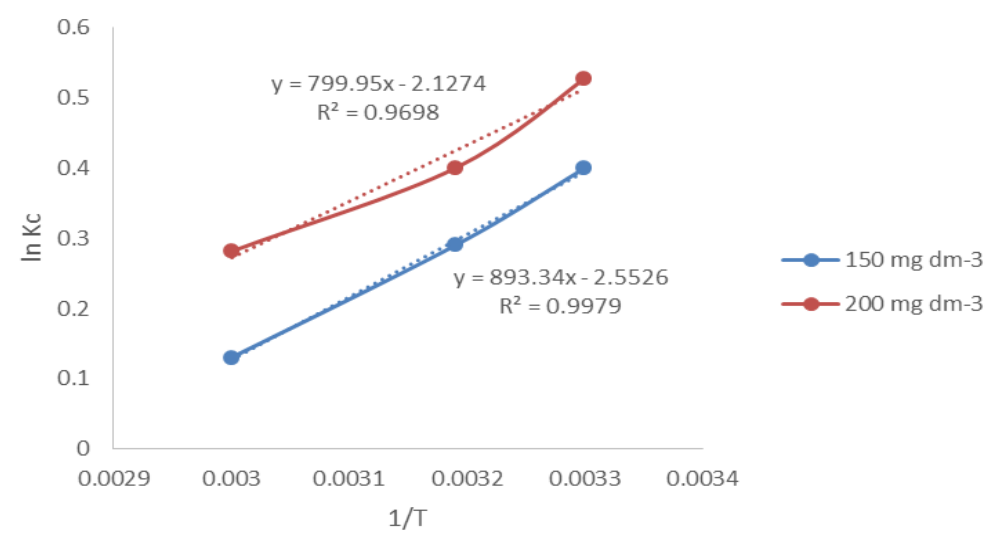

Fig. 9. Plot of $\ln \mathrm{K}_{\mathrm{c}}$ versus $1 / \mathrm{T}$ for $\mathrm{Cr}(\mathrm{VI})$ adsorption onto LAC

Table 2. Thermodynamic parameters for Cr(VI) adsorption onto LAC

\begin{tabular}{llllll}
\hline $\mathrm{C}_{0}\left(\mathrm{mgdm}^{-3}\right)$ & $\Delta \mathrm{H}\left(\mathrm{kJ} \mathrm{mol}^{-1}\right)$ & $\Delta \mathrm{S}\left(\mathrm{kJ} \mathrm{mol}^{-1} \mathrm{~K}^{-1}\right)$ & \multicolumn{3}{c}{$\Delta \mathrm{G}\left(\mathrm{kJ} \mathrm{mol}{ }^{-1}\right)$} \\
\cline { 3 - 5 } & & & $303 \mathrm{~K}$ & $313 \mathrm{~K}$ & $323 \mathrm{~K}$ \\
\hline 150 & -7.427 & -0.021 & -1.005 & -0.624 & -0.349 \\
200 & -6.650 & -0.018 & -1.329 & -0.948 & -0.755 \\
\hline
\end{tabular}

\subsection{Comparison of Cr(VI) adsorption capacity of LAC with other reported adsorbents}

To justify the potential of LAC as an efficient adsorbent for chromium removal, a comparison of the maximum $\mathrm{Cr}(\mathrm{VI})$ adsorption capacity of the prepared adsorbent has been carried out with other reported adsorbents and the summary is presented in Table 3. It is pertinent to note that this comparison has a relative interpretation due to some factors, such as different experimental conditions (adsorbent dosage, $\mathrm{pH}$, temperature, adsorbate concentration, agitation rate, shaking versus stirring), method (batch versus column) and type of biomaterial employed in each referenced study. Nonetheless, the maximum adsorption capacity of LAC for $\mathrm{Cr}(\mathrm{VI})$ is comparable and moderately higher than that of many of the reported sorbent materials of similar category. The implications were that LAC is a promising adsorbent for treatment of chromium-bearing water and wastewater. 
Table 3. Comparison of Cr(VI) adsorption capacities of activated carbons from different sources

\begin{tabular}{lllll}
\hline Activated carbon source & $\mathrm{q}_{\max }\left(\mathrm{mg} \mathrm{g}^{-1}\right)$ & Optimum pH & $\begin{array}{l}\text { Max. Cr concentration used (mg } \\
\left.\mathrm{dm}^{-3}\right)\end{array}$ & Reference \\
\hline Almond shell & 165.70 & 2.0 & 1000 & 49 \\
Ziziphus jujuba cores & 196.38 & 2.0 & 500 & 50 \\
Activated charcoal & 2.60 & 4.0 & 50 & 51 \\
Palmyra palm seed & 32.14 & $1.0-2.0$ & 200 & 52 \\
Juniperus procera leaves & 23.00 & 4.0 & 300 & 53 \\
Rice husk & 34.85 & 2.0 & 250 & 54 \\
Peanut shell & 8.31 & 2.0 & 100 & 55 \\
Palm kernel shell & 125.00 & 2.0 & 100 & 56 \\
Walnut shell & 6.12 & 2.0 & 100 & 57 \\
Bamboo waste & 59.23 & 2.0 & 150 & 58 \\
Apple peels & 36.01 & 2.0 & 50 & 59 \\
Macadamia nutshell & 22.30 & 2.0 & 150 & 60 \\
Desert date seed shell & 99.09 & 2.0 & 250 & This study \\
\hline
\end{tabular}

\section{Conclusion}

There are numerous existing techniques for removal of chromium, each with their merits and limitations. Operational and cost effectiveness are the important characters that makes adsorption stands out among other conventional techniques. In the present work, a lignocellulosic waste is employed for making activated carbon which was successfully utilized for $\mathrm{Cr}(\mathrm{VI})$ removal from aqueous medium. The studied material is quite promising because of its abundance, low-cost and little processing. Operational variables like $\mathrm{pH}$, contact time, initial concentration, coexisting ions, adsorbent dosage and temperature were found to influence the adsorption capacity of the prepared adsorbent significantly. The equilibrium data fit well to Freundlich isotherm model, indicating multilayer adsorption. The negative values of $\Delta \mathrm{G}^{\circ}$ confirmed the spontaneity of the adsorption process. The negative values of $\Delta \mathrm{H}^{\circ}$ and $\Delta \mathrm{S}^{\circ}$ indicated exothermic and enthalpy driven nature of $\mathrm{Cr}(\mathrm{VI})$ adsorption. The considerable adsorption capacity of $99.09 \mathrm{mg} \mathrm{g}^{-1}$ is signifier of the suitability of the prepared adsorbent for commercial application. The present study concludes that LAC could be employed as an alternative low-cost adsorbent for the removal from of $\mathrm{Cr}(\mathrm{VI})$ from water and wastewater.

The expected contribution of this research include the following: (a) conversion of desert date seed shell into activated carbon will lessen the problem of disposal and management of this agro-waste, while providing valuable end-product for water treatment that could potentially expand the activated carbon market; (b) benefit industries especially those dealing with $\mathrm{Cr}(\mathrm{VI})$ compounds through the availability of cost-effective treatment approach; (c) contribution to existing data on wastewater treatment especially in chromium adsorption for future research. A follow-up research in the following direction is needed to substantiate the potential of activated carbon prepared in the current work for large scale application: (a) the feasibility of recovery and recycling of the exhausted carbon should be investigated; (b) dynamic/column adsorption studies should be conducted for design perfection purposes; (c) study of the adsorption behavior from quantum-chemical perspective for precise mechanistic insights.

\section{References}

[1] Chen, Y., An, D., Sun, S., Gao, J. and Linping, Q. (2018). Reduction and Removal of Chromium VI in Water by Powdered Activated Carbon. Materials, 269(11):1-12.

[2] Ali, I. H., Al Mesfer, M.K., Khan, M.I., Danish, M. and Alghamdi, M.M. (2019). Exploring Adsorption Process of Lead (II) and Chromium (VI) Ions from Aqueous Solution on Acid Activated Carbon Prepared from Juniperus procera Leaves. Processes, 7:1-14. 
[3] Kumar, G.V.S.R.P., Avinash, M.K., Bharath, Y., and Rao, K.S. (2019). Removal of Hexavalent Chromium from Aqueous Solution using Low Cost Adsorbents and ANN Modelling for Prediction. Journal of Indian Chemical Society, 96:1-8.

[4] Hegazi, H.A. (2013). Removal of Heavy Metals from Wastewater using Agricultural and Industrial Wastes as Adsorbents. HBRC Journal, 9:276-282.

[5] Zare, E.N., Motahari, A., Sillanpaa, M. (2018). Nanoadsorbents Based on Conducting Polymer Nanocomposites with Main Focus on Polyaniline and its Derivatives for Removal of Heavy Metal Ions/Dyes: A Review. Environmental Research, 162:173-195.

[6] Maitlo, H.A., Kim, K.H., Park, Y.J., Khan, A. (2019). Metal-air Fuel Cell Electrocoagulation Technique for the Treatment of Arsenic in Water. Journal of Cleaner Production, 207:67-84.

[7] Jin, L., Huang, L., Ren, L., He, Y., Tang, J., Wang, S., Yang, W., Chai, L. (2019). Preparation of Stable and High-Efficient Poly(m-phenylenediamine)/Reduced Graphene Oxide Composites for Hexavalent Chromium Removal. Journal of Material Science, 54:383-395.

[8] Hassan, R., Arida, H., Montasser, M., Latif, N.A. (2013). Synthesis of New Schiff Base from Natural Products for Remediation of Water Pollution with Heavy Metals in Industrial Areas. Journal of Chemistry, Article ID: 240568.

[9] Ibrahim, M.B. (2013). Thermodynamics and Adsorption Efficiencies of Maize Cob and Sawdust for the Remediation of Toxic Metals from Wastewater. Journal of Geoscience and Environment Protection, 1(2): $18-21$.

[10] Ibrahim, M.B. and Jimoh, W.L.O. (2012). Thermodynamics and Adsorption Isotherms for the Biosorption of Cr(VI), Ni(II) and Cd(II) onto Maize Cob. Chemsearch Journal, 3(1):7-12.

[11] Kobya, M. (2004). Removal of Cr (VI) from aqueous solution by adsorption onto hazelnut shell activated carbon: kinetic and equilibrium studies. Bioresource Technology 91:317-321.

[12] Owalude, S.O. and Tella, A.C. (2016). Removal of Hexavalent Chromium from Aqueous Solution by Adsorption on Modified Groundnut Hull. Beni-Suef University Journal of Basic and Applied Science, 5(4):377-388.

[13] Kumari, P. (2017). Application of sugarcane bagasse for the removal of Cr(VI) and Zn(II) from aqueous solution. International Research Journal of Engineering and Technology, 4(2):1670-1673.

[14] Sharma. P.K., Ayub, S. and Tripath, C.N. (2016). Isotherms Describing Physical Adsorption of Cr(VI) from Aqueous Solution using Various Agricultural Wastes s Adsorbents. Cogent Engineering 3:1-20.

[15] Mekonnen, E., Yitbarek, M. and Soreta, T.R. (2015). Kinetic and Thermodynamic Studies of the Adsorption of $\mathrm{Cr}(\mathrm{VI})$ onto Some Selected Local Adsorbents. South African Journal of Chemistry, 68:45-52.

[16] Malkoc, E. and Nuhoglu, Y. (2007). Potential Tea Factory Waste for Chromium (VI) Removal from Aqueous Solution; Thermodynamic and Kinetic Studies. Separation Purification Technology, 54:291-298.

[17] Demiral, H., Demiral, I., Tumsek, F. and Karabacakoglu, B. (2008). Adsorption of Chromium (VI) from Aqueous Solution by Activated Carbon Derived from Olive Bagasse and Applicability of Different Adsorption Models. Chemical Engineering Journal, 144:188-196.

[18] Pakade, V.E., Tavengwa, N.T. and Madikizela, L.M. (2019). Recent Advances in Hexavalent Chromium Removal from Aqueous Solutions by Adsorptive Methods. RSC Advance, 9:26142-26164. 
[19] Yusuff, A.S. (2019). Adsorption of Hexavalent Chromium from Aqueous Solution by Leucaena Leucocephala Seed Pod Activated Carbon: Equilibrium, Kinetic and Thermodynamic Studies. Arab journal of Basic and Applied Science, 26(1):89-102.

[20] Asadullah, Kaewsichan L, Tohdee K. (2019). Adsorption of Hexavalent Chromium onto Alkali-Modified Biochar Derived from Lepironia articulata: a Kinetic, Equilibrium, and Thermodynamic Study. Water Environment Research;1-14.

[21] Manjuladevi, M. and Manonmani, S. (2015). Removal of Hexavalent Chromium from Aqueous Solution by Adsorption using Activated Carbon Prepared from Cucumis melo Peel. Oriental Journal of Chemistry 31 (1):1-8.

[22] Singh, S.K. (2017). Removal of Hexavalent Chromium by using Sugarcane Bagasse as a Low-Cost Adsorbent. Indian Journal of Scientific Research, 13(1):73-76.

[23] Wang, X., Wang, S., Yin, X., Chen, J. and Zhu, L. (2014). Activated Carbon Preparation from Cassava Residue Using a Two-Step KOH Activation: Preparation, Micropore Structure and Adsorption Capacity. Journal of Biobased Materials and Bioenergy, 8(20):1-8.

[24] Bakatula, E.N., Richard, D., Neculita, C.M. and Zagury, G.J. (2018). Determination of Point of Zero Charge of Natural Organic Materials. Environmental Science and Pollution Research, 25(8):7823-7833.

[25] Mahmood, T. Saddique, M.T., Naeem, A., Westerhoff, P. Mustafa, S. and Alum, A. (2011). Comparison of Different Methods for the Point of Zero Charge Determination of NiO. Industrial and Environmental Chemistry Research, 50:10017-10023.

[26] Abbas, M., Harrache, Z. and Trari, M (2019). Removal of Gentian Violet in Aqueous Solution by Activated Carbon Equilibrium, Kinetics, and Thermodynamic Study. Adsorption Science \& Technology 37(7-8):566-589.

[27] Rai, M.K., Shahi, G., Meena, R., Meena, S., Chackraborty, S., Singh, R.S and Rai. B.N (2016) Removal of Hexavalent Cr (VI) using Activated Carbon Prepared from Mango Kernel Activated with H3PO4. Resource-Efficient Technologies, 2:S63-S70.

[28] Radnia, H., Ghoreyshi, A.A., Younesi, H. (2012). Adsorption of Fe(II) by Chitosan Adsorbent: Equilibrium, Kinetic, and Thermodynamic Studies. Desalination and Water Treatment, 50:348-359.

[29] Maremeni, L.C., Modise, S.J., Mtunzi, F.M., Klink, M.J. and Pakade, V.E (2018). Adsorptive Removal of Hexavalent Chromium by Di-phenylcarbazide-Grafted Macadamia Nutshell Powder. Bioinorganic Chemistry and Applications. Article ID: 6171906.

[30] Babel, S. and Kurniawan, T.A. (2004). Cr(VI) Removal from Synthetic Wastewater Using Coconut Shell Charcoal and Commercial Activated Carbon Modified with Oxidizing Agents and/or Chitosan. Chemosphere, 54:951-967.

[31] Katal, R., Ghiass, M and Estafandian, H. (2011). Application of Nanometer Size Polypyrole as a Suitable Adsorbent for Removal of Cr (VI). Journal of Vinyl \& Additive Technology, 17:222-230.

[32] Zhao, Y., Yang, S., Ding, D., Chen, J., Yang, Y., Lei, Z., Feng, C. and Zhang, Z. (2013). Effective Adsorption of $\mathrm{Cr}(\mathrm{VI})$ from Aqueous Solution using Natural Akadama Clay. Journal of Colloid and Interface Science, 395:198-204.

[33] Alemu, A., Lemma, B., Gabbiye, N., Alula, M.T., Desta, M.T. (2018). Removal of Chromium (VI) from Aqueous Solution using Vesicular Basalt: A Potential Low Cost Wastewater Treatment System. Heliyon, Article no-e00682. 
[34] Demirbas, E., Kobya, M., Senturk, E. and Ozkan, T. (2004). Adsorption Kinetics for the Removal of Chromium (VI) from Aqueous Solution on the Activated Carbon Prepared from Agricultural Wastes. Water. 30(4): 533-540.

[35] Ibrahim, M.B. and Jimoh, W.L.O (2011). Remediation of Cr and Fe from Aqueous Solution by Natural Adsorbents. International Journal of Biological and Chemical Sciences 5(3): 915-922.

[36] Parlayici, S. and Pehlivan, E. (2019). Comparative Study of Cr(VI) Removal by Bio-waste Adsorbents: Equilibrium, Kinetics and Thermodynamic. Journal of Analytical Science and Technology, 10(15):1-8.

[37] Kumar, G.V.S.R.P., Avinash, M.K., Bharath, Y., and Rao, K.S. (2019). Removal of Hexavalent Chromium from Aqueous Solution using Low Cost Adsorbents and ANN Modelling for Prediction. Journal of Indian Chemical Society, 96:1-8.

[38] Pathan, S.A. and Pandita, N.S. (2016). Nanoporous Carbon Synthesized from Grass for Removal and Recovery of Hexavalent Chromium. Carbon Letters, 20:10-18.

[39] Futalan, C.M., Tsai, W.C., Lin, S.S., Hsien, K.J. Dalida, M.L., Wan, M.W. (2012). Copper, Nickel and Lead Adsorption from Aqueous Solution using Chitosan-Immobilized on Bentonite in Ternary System. Sustainable Environment Research, 22(6):345-355.

[40] Sahbaz, D. A, Dandil, S. and Acikgoz, C. (2019). Removal of Crystal Violet Dye by a Novel Adsorbent Derived from Waste Active Sludge used in Wastewater Treatment. Water Quality Research Journal, 54(4):299-308.

[41] Bayuo, J., Pelig-Ba, K.B. and Abukari, M.A. (2019). Adsorptive Removal of Chromium(VI) from Aqueous Solution unto Groundnut Shell. Applied Water Science, 9(107):1-11.

[42] Odoemelam, S.A., Emeh, U.N., and Eddy, N.O. (2018). Experimental and Computational Chemistry Studies on the Removal of Methylene Blue and Malachite Green Dyes from Aqueous Solution by Neem (Azadirachta Indica) Leaves. Journal of Taibah University for Science. 12(3):255-265.

[43] Gupta, S. and Babu, B. V. (2009). Removal of Toxic Metal Cr(VI) from Aqueous Solution using Sawdust as Adsorbent: Equilibrium, Kinetics and Regeneration Studies. Chemical Engineering Journal. 150:1 352-365.

[44] Chen, B., Yue, W., Zhao, H., Long, F., Cao, Y. and Pan, X. (2019). Simultaneous Capture of Methyl Orange and Chromium(VI) from Complex Wastewater using Polyethylenimine Cation Decorated Magnetic Carbon Nanotubes as a Recyclable Adsorbent. RSC Advance 9:4722-4734.

[45] Chackraborty, S., Chowdury, S. and Saha, P.D. (2011). Adsorption of Crystal Violet from Aqueous Solution onto NaOH-modified Rice Husk. Carbohydrate Polymers. 86:1533-1541.

[46] Gorzin, F. and Abadi, M.M.B.R. (2017) Adsorption of Cr(VI) from Aqueous Solution by Adsorbent Prepared from Paper Mill Sludge: Kinetics and Thermodynamic Studies. Adsorption Science \& Technology, 36(1-2):149-169.

[47] Gupta, V.K., Jain, R., Siddiqui, M.N. Saleh, T.A., Agarwal, S., Malati, S. and Pathak, D. (2010). Equilibrium and Thermodynamic Studies on the Adsorption of the Dye Rhodamine-B onto Mustard Cake and Activated Carbon. Journal of Chemical Engineering Data, 55:5225-5229.

[48] Aslani, H., Kosari, T.E., Naseri, S., Nabizadeh, R. and Khazaei, M. (2018). Hexavalent Chromium Removal from Aqueous Solution Using Functionalized Chitosan as Novel Nano-adsorbent: Modeling and Optimization, Kinetic, Isotherm and Thermodynamic Studies and Toxicity Testing. Environmental Science and Pollution Research, 25(20):20154-20168. 
[49] Rai, M.K., Giri, B.S., Nath Y., Bajaj, H., Soni, R.P., Singh, R.S. and Rai., B.N. (2018). Adsorption of Hexavalent Chromium from Aqueous Solution by Activated Carbon Prepared from Almond Shell: Kinetics, Equilibrium and Thermodynamics Study. Journal of Water Supply: Research and Technology, 67(8):724-737.

[50] Labied, R., Benturki, O., Hamotouche, A. and Donnot, A. (2018). Adsorption of Hexavalent Chromium by Activated Carbon Obtained from a Waste Lignocellulosic Material (Ziziphus jujuba cores): Kinetic, Equilibrium, and Thermodynamic Study. Adsorption Science and Technology 0(0):1-34.

[51] Dragan, C., Pantilimon, C., Predescu, A., Coman, G., Matei, E. and Predescu, C. (2018). Removal of Cr (VI) from Aqueous Solution using Activated Charcoal. International Journal of Chemistry and Chemical Engineering Systems. 3:11-15

[52] Kannan, A. and Thambidurai, S. (2008). Removal of Hexavalent Chromium from Aqueous Solution Using Activated Carbon Derived from Palmyra Palm Fruit Seed. Bulletin of Chemical Society of Ethiopia 22(2):183-196.

[53] Ali, I. H., Al Mesfer, M. K., Khan, M. I., Danish, M. and Alghamdi, M.M. (2019). Exploring Adsorption Process of Lead (II) and Chromium (VI) Ions from Aqueous Solution on Acid Activated Carbon Prepared from Juniperus procera Leaves. Processes, 7:1-14.

[54] Mullick, A., Moulik, S. and Bhattacherjee, S. (2018). Removal of Hexavalent Chromium from Aqueous Solution by Low-Cost Rice Husk-Based Activated Carbon: Kinetic And Thermodynamic Studies. Indian Chemical Engineer, 60(1):58-71.

[55] Al-Othman, Z.A., Ali, R. and Naushad, M. (2012). Hexavalent Chromium Removal from Aqueous Medium by Activated Carbon Prepared from Peanut Shell: Adsorption Kinetics, Equilibrium and Thermodynamic Studies. Chemical Engineering Journal. 184:238-247.

[56] Mehr, M.R., Fekri, M.H., Omidali, F., Eftekhari, N., Akbari-adergani, B. (2019). Removal of Chromium (VI) from Wastewater by Palm Kernel Shell-Based on a Green Method. Journal of Chemical Health Risks, 9(1):75-86.

[57] Nethaji, S. and Sivasamy, A. (2014). Removal of Hexavalent Chromium from Aqueous Solution using Activated Carbon Prepared from Walnut Shell Biomass Through Alkali Impregnation Processes. Clean Technologies and Environmental Policy, 16:361-368.

[58] Dula, T., Siraj, K., Kitte, S.A. (2014). Adsorption of Hexavalent Chromium from Aqueous Solution Using Chemically Activated Carbon Prepared from Locally Available Waste of Bamboo (oxytenanthera abyssinica). Environmental Chemistry, Article ID: 438245.

[59] Enniya, I., Rghioui, L., Jourani, A. (2018). Adsorption of Hexavalent Chromium in Aqueous Solution on Activated Carbon Prepared from Apple Peels. Sustainable Chemistry and Pharmacy, 7:9-16.

[60] Pakade, V.E., Nchoe, O.B., Hlungwane, L., Tavengwa, N.T. (2017). Sequestration of Hexavalent Chromium from Aqueous Solution by Activated Carbon Derived from Macadamia Nutshells. Water Science and Technology, 75(1):196-206. 


\section{Authors' Profiles}

Umar Yunusa received the Bachelor's degree in Chemistry from Ahmadu Bello University, Zaria, Kaduna, Nigeria, and the Master's degree in Chemistry with specialization in Physical Chemistry from Bayero University, Kano. He has about 4 years' experience in teaching and research. He is a member of the chemical society of Nigeria. His areas of research interest is environmental pollution and remediation studies using adsorption technique.

Muhammad Bashir Ibrahim is an energetic professor of physical chemistry currently working with Bayero University, Kano, Nigeria. He has over 25 years' experience in teaching and Research. He is member of professional bodies like the Chemical Society of Nigeria (CSN) and Institute of Chartered Chemist of Nigeria (ICCON). He has over 50 scholarly publications in reputable journals. His area of research interest include wastewater treatment, corrosion control and biophysical researches of bio-macromolecules.

How to cite this paper: Umar Yunusa, Muhammad Bashir Ibrahim. "Equilibrium and Thermodynamic Studies on Adsorption of Hexavalent Chromium from Aqueous Solution onto Low Cost Activated Carbon", International Journal of Engineering and Manufacturing(IJEM), Vol.10, No.2, pp.52-70, 2020. DOI: 10.5815/ijem.2020.02.05 